\title{
ADAM15 participates in fertilization through a physical interaction with acrogranin
}

\author{
Karina Pastén, Yadira Bastian², Ana L Roa-Espitia, Deneb Maldonado-García, \\ Guillermo Mendoza-Hernández , Cesar I Ortiz-García, Adela Mújica and \\ Enrique O Hernández-González
}

Departamento de Biología Celular, Centro de Investigación y de Estudios Avanzados del Instituto Politécnico Nacional (CINVESTAV-IPN), No. 2508, México, Distrito Federal, México CP $07360{ }^{1}$ Departamento de Bioquímica, Facultad de Medicina, Universidad Nacional Autónoma de México (UNAM), México, Distrito Federal, México CP 04510

and ${ }^{2}$ Instituto de Física, Universidad Autónoma de San Luis Potosí, San Luis Potosí, México CP 78290

Correspondence should be addressed to E O Hernández-González; Email: eoton@cell.cinvestav.mx

\begin{abstract}
Mammalian fertilization is completed by direct interaction between sperm and egg. This process is primarily mediated by both adhesion and membrane-fusion proteins found on the gamete surface. ADAM1, 2, and 3 are members of the ADAMs protein family, and have been involved in sperm-egg binding. In this study, we demonstrate the proteolytic processing of ADAM15 during epididymal maturation of guinea pig spermatozoa to produce a mature form a size of $45 \mathrm{kDa}$. We find that the size of the mature ADAM15, $45 \mathrm{kDa}$, in cauda epididymal spermatozoa indicates that the pro-domain and metalloprotease domain are absent. In addition, using indirect immunofluorescence, ADAM15 was found throughout the acrosome, at the equatorial region and along the flagellum of guinea pig spermatozoa. After acrosome reaction, ADAM15 is lost from the acrosomal region and retained in the equatorial region and flagellum. In this study, we also report the first evidence of a complex between ADAM15 and acrogranin. By immunoprecipitation, we detected a protein band of $65 \mathrm{kDa}$ which co-immunoprecipated together ADAM15. Analysis of the N-terminal sequence of this $65 \mathrm{kDa}$ protein has revealed its identity as acrogranin. In addition, using cell-surface labeling, ADAM15 was found to be present on the cell surface. Assays of heterologous fertilization showed that the antibody against acrogranin inhibited the sperm-egg adhesion. Interestingly, ADAM15 and acrogranin were also found associated in two breast cancer cell lines. In conclusion, our results demonstrated that ADAM15 and acrogranin are present on and associated with the surface of guinea pig spermatozoa; besides both proteins may play a role during sperm-egg binding.

Reproduction (2014) 148 623-634
\end{abstract}

\section{Introduction}

Mammalian fertilization is the result of a set of molecular events that enable the acrosome-reacted spermatozoa to recognize, bind, and fuse with the egg membrane. In order to fertilize an egg, the mammalian spermatozoa must undergo a series of biochemical and functional changes during epididymal maturation and in the female genital tract, such as capacitation and acrosome reaction. It is known that only acrosome-reacted spermatozoa are able to recognize, bind, and fuse with the egg plasma membrane (Evans 2012).

The sperm-egg interaction is a key step for fertilization; although unclear, this process is mediated primarily by gamete surface proteins. Therefore, in order to gain insights into sperm-egg interaction, it is essential to explore the capabilities of proteins found on the gamete surface to participate in such interaction. Some of these adhesion proteins are gamete specific and othersare more widely expressed (Rubinstein et al. 2006). For instance, the disintegrin metalloprotease proteins ADAMs are implicated in the fertilization processes (Cho et al. 1998, Shamsadin et al. 1999, Nishimura et al. 2001, Zhu et al. 2001). ADAMs proteins consist of an $\mathrm{N}$-terminal signal sequence, followed by a pro-domain, a metalloprotease domain, a disintegrin-like domain, and a cysteine-rich region. In most cases, these proteins also include an epidermal growth factor (EGF) repeat, a transmembrane domain, and a cytoplasmic tail. The heterodimer ADAM1/ADAM2, also known as fertilin $\alpha / \beta$, which plays an important role in sperm-egg interaction during fertilization, is the best-studied of the ADAM family (Myles et al. 1994, Evans et al. 1995, Cho et al. 1998, Chen et al. 1999). Another well-studied example is ADAM15, which is expressed on the surface of a wide range of somatic cells and in mouse spermatozoa, has a role as an adhesion protein (Herren et al. 1997, 2001, 
Poghosyan et al. 2002, Pasten-Hidalgo et al. 2008). We have recently reported that ADAM15 is expressed in mouse spermatozoa. Also, we described the posttranslational processing that ADAM15 undergoes during epididymal sperm maturation and acrosome reaction. Moreover, when the disintegrin domain of ADAM15 was used, a partial inhibition of sperm-egg fusion as well as an almost complete inhibition of sperm-oolema adhesion was found (Pasten-Hidalgo et al. 2008).

Acrogranin, also known as progranulin, granulinepithelin precursor, PC cell-derived growth factor, and proepithelin, is a secreted growth factor of high molecular weight, implicated in cell growth, wound repair, renal cysts formation, tumorigenesis, inflammation, neurodevelopment, and neurodegeneration. Acrogranin also mediates cell cycle progression and cell motility (He \& Bateman 2003, He et al. 2003, De Muynck \& Van Damme 2011). Acrogranin activates both the PI3K and ERK pathway, and promotes the expression of cyclin D1 and cyclin B (He \& Bateman 2003, He et al. 2003). In addition, acrogranin has been involved in cell adhesion; antibodies against acrogranin block blastocyst adhesion whereas addition of purified acrogranin increases it (Qin et al. 2005). It has been reported that acrogranin as a glycoprotein of $67 \mathrm{kDa}$ is expressed in guinea pig spermatozoa, solely located in the acrosome region (Anakwe \& Gerton 1990). Acrogranin has also been involved in acrosome biogenesis; nevertheless, the function of acrogranin in mature sperm is still unknown.

To extend our knowledge of the role of ADAM15 in mature sperm cells, we examined the ability of ADAM 15 to interact with other proteins and evaluated its participation on the sperm-egg interaction. Our results show that ADAM15 is fully processed proteolytically before the acrosome reaction takes place and that after the acrosome reaction ADAM15 is localized in the equatorial segment where it associates with acrogranin. Moreover, we find that masking acrogranin with a specific anti-acrogranin antibody severely decreases the process of fertilization. In addition, the ADAM15-acrogranin interaction was also detected in two cancer cell lines.

\section{Materials and methods \\ Antibodies and reagents}

Rabbit polyclonal antibody against the carboxyl terminal region of ADAM15 (ADAM15-CT) was obtained from Oncogene Research Products (Boston, MA, USA). Goat polyclonal antibodies against ADAM-15- $\mathrm{NH}_{2}(\mathrm{~V}-20)$ and acrogranin (M-12) were purchased from Santa Cruz Biotechnology. HRP-conjugated anti-rabbit, TRITC-conjugated anti-rabbit, and TRITC-conjugated anti-goat antibodies were purchased from Jackson ImmunoResearch (West Grove, PA, USA). HRP-labeled streptavidin was obtained from Pierce (Rockford, IL, USA). Pyruvic acid, DL-dithiothreitol (DTT), trizma base, Tween-20, pepstatin, leupeptin, phenylmethylsulfonyl fluoride (PMSF), benzamidine, soybean trypsin inhibitor, and iodoacetamide were purchased from Sigma Chemical Co. Complete mini protease inhibitor cocktail and protein A-agarose were obtained from Roche. Sulfo-NHS-LC-biotin was purchased from Pierce. Nitrocellulose membrane was purchased from Bio-Rad. PVDF-blotting membranes were from Millipore Corporation (Bedford, MA, USA). Sodium lauryl sulfate (SDS) was obtained from Calbiochem (San Diego, CA, USA). ECL detection kits were from Amersham Pharmacia Biotechnology.

\section{Animals}

All animal handling procedures and experimental design were approved by the Internal Committee for the Care and Use of the Laboratory Animals, CINVESTAV-IPN (CICUAL No. 321-02), following the American Veterinary Medical Association guidelines. All efforts were made to minimize the potential for animal pain, stress, or distress.

\section{Preparations of testicular cells and epididymal sperm}

Testicular cells were isolated from adult guinea pig testes as described by Phelps \& Myles (1987). The animals were killed by $\mathrm{CO}_{2}$ asphyxiation, and testes were quickly removed and stripped of fat pad and epididymis. The tissue was chopped into small pieces with a razor blade and the fragments were vigorously pipetted with wide bore pipette. The extract was filtered through a nylon mesh to remove connecting tissue and debris. The epididymal sperm were removed from the three epididymal regions (caput, distal corpus, and distal cauda) after dissection (Hoffer \& Greenberg 1978) by expressing the spermatozoa from the epididymal tube using a wooden applicator stick. The sperm were washed twice in PBS by resuspension-centrifugation.

\section{Sperm capacitation}

The spermatozoa were obtained from the vas deferens using $154 \mathrm{mM} \mathrm{NaCl}$ (saline), and washed twice by suspensioncentrifugation in saline (non-capacitated spermatozoa) as previously described (Trejo \& Mujica 1990). For capacitation, the sperm cells were incubated for $2 \mathrm{~h}$ at $37^{\circ} \mathrm{C}$ in minimal culture medium with pyruvate and lactate (MCM-PL: $105.1 \mathrm{mM} \mathrm{NaCl}, 1.7 \mathrm{mM} \mathrm{CaCl} \cdot 2 \mathrm{H}_{2} \mathrm{O}, 25.1 \mathrm{mM} \mathrm{NaHCO}$, $0.25 \mathrm{mM}$ pyruvate, and $20 \mathrm{mM}$ lactic acid of $\mathrm{pH}$ 7.8) (Rogers \& Yanagimachi 1975 ) at a concentration of $35 \times 10^{6}$ cells $/ \mathrm{ml}$. After $2 \mathrm{~h}$ of incubation in MCM-PL, spontaneous acrosomereacted cells were observed, this is, spermatozoa without acrosome and with hyperactive motility.

\section{Immunofluorescence assays}

Testicular cells, epididymal sperm, non-capacitated spermatozoa, and capacitated gametes (with and without acrosome reaction) were fixed in $3.0 \%(\mathrm{v} / \mathrm{v})$ formaldehyde in PBS. After $1 \mathrm{~h}$, the spermatozoa were collected by centrifugation. The pelleted spermatozoa (at $600 \mathrm{~g}$ for $3 \mathrm{~min}$ ) were incubated in $50 \mathrm{mM} \mathrm{NH}_{4} \mathrm{Cl}$ for $10 \mathrm{~min}$, rinsed twice with PBS and once with bi-distilled water. The spermatozoa were resuspended in 
bi-distilled water. This suspension was spread on microscope slides and air-dried at room temperature. Then, the cells were permeabilized in absolute acetone for $7 \mathrm{~min}$ at $-20^{\circ} \mathrm{C}$ and washed with PBS. ADAM15 and acrogranin-specific antibodies were used at a dilution of $1: 100$ and $1: 50$ respectively. The sperm cells were incubated for $1 \mathrm{~h}$ at $37^{\circ} \mathrm{C}$ with $1 \%$ BSA in PBS used as a blocking solution. The samples were washed in PBS. Next, they were incubated for $2 \mathrm{~h}$ at $37^{\circ} \mathrm{C}$ with the appropriated TRIC-conjugated anti-rabbit or TRIC-conjugated anti-goat secondary antibodies at a 1:100 dilution in a blocking solution. After three washes with PBS, the samples on slides were mounted under cover glass slides using Gelvatol for observation and analysis under the microscope. Some samples were fixed and permeabilized after to be stained in vivo. The cells were viewed with a Zeiss photomicroscope equipped with phase-contrast and epifluorescence optics or by confocal microscopy, Leica TCS SP2.

\section{Western blotting analysis}

Testicular cells, epididymal spermatozoa and non-capacitated spermatozoa, capacitated, and acrosome-reacted sperm were collected by centrifugation at $600 \mathrm{~g}$ for $3 \mathrm{~min}$, washed twice with PBS, and then solubilized in lysis buffer (1\% NP-40 in PBS) supplemented with a set of protease inhibitors: $1 \mathrm{mM}$ PMSF, $2 \mu \mathrm{g} / \mathrm{ml}$ leupeptin, $2 \mu \mathrm{g} / \mathrm{ml}$ pepstain, $50 \mu \mathrm{g} / \mathrm{ml}$ benzamidine, $1 \mu \mathrm{g} / \mathrm{ml}$ soybean trypsin inhibitor, $10 \mu \mathrm{g} / \mathrm{ml}$ iodoacetamide, and $30 \mu \mathrm{l} / \mathrm{ml}$ of a commercial mixture of the protease inhibitor $\mathrm{H}_{2} \mathrm{O}$ complete. The samples were then incubated for $20 \mathrm{~min}$ on ice and centrifuged at $10000 \mathrm{~g}$ for $20 \mathrm{~min}$ at $4{ }^{\circ} \mathrm{C}$. The supernatants were collected and their protein concentration was determined (Bradford 1976). For protein disulfide reduction, supernatant aliquots were boiled for $5 \mathrm{~min}$ in Laemmli buffer (Laemmli 1970) containing $720 \mathrm{mM} 2$-mercaptoethanol and then applied to SDS-PAGE gels. To determine physical interactions between DAM15 and acrogranin, we followed the method described by Blobel et al. (1990): the supernatant samples were treated with $0.5 \%$ SDS at room temperature in Laemmli buffer without 2-mercaptoethanol and separated by SDS-PAGE. After electrophoresis, the proteins were transferred to nitrocellulose membranes, which were then blocked with $5 \%$ fat-free dry milk in TBS-Tween $(10 \mathrm{mM}$ Tris- $\mathrm{HCl}, 150 \mathrm{mM} \mathrm{NaCl}, 1.0 \%$ Tween, $\mathrm{pH}$ 7.5). The membranes were incubated overnight at $4{ }^{\circ} \mathrm{C}$ with anti-ADAM15-CT (1:100 dilution) or anti-ADAM15NT (1:400 dilution). After five washes with TBS-Tween, the membranes were incubated with HRP conjugated-secondary antibodies (1:7500 dilution). Immunoreactive proteins were detected by chemiluminescence using an ECL Kit.

\section{Cell surface labeling and immunoprecipitation analysis}

The noncapacitated and acrosome-reacted spermatozoa were collected as described earlier, washed twice with PBS, resuspended in $4 \mathrm{ml}$ of PBS containing $2 \mathrm{mg}$ Sulfo-NHSLC-biotin and incubated at $4{ }^{\circ} \mathrm{C}$ for $45 \mathrm{~min}$. The biotinylated cell samples were then washed twice with PBS and blocked with $50 \mathrm{mM}$ glycine in TBS. Afterward, the cells were resuspended in lysis buffer with protease inhibitors, incubated on ice for $20 \mathrm{~min}$, and centrifuged at $10000 \mathrm{~g}$ at $4{ }^{\circ} \mathrm{C}$ for $15 \mathrm{~min}$. For biotinylation of total cell lysate, non-capacitated cells were lysed first in cell lysis buffer and then incubated with Sulfo-NHS-LC biotin for $45 \mathrm{~min}$, and finally blocked with $50 \mathrm{mM}$ glycine in TBS. The supernatants containing $500 \mu \mathrm{g}$ of solubilized proteins were incubated overnight with anti-ADAM15 CT-1 $(1 \mu \mathrm{g} / \mathrm{ml}$ at $4{ }^{\circ} \mathrm{C}$ under end-to-end rotation). This antibody was incubated early on with $\mathrm{A} / \mathrm{G}$ protein-agarose for $30 \mathrm{~min}$. The immune complexes were collected by centrifugation for $15 \mathrm{~min}$ at $4{ }^{\circ} \mathrm{C}$ at $10000 \mathrm{~g}$ and then washed three times with $200 \mu \mathrm{l}$ of PBS. The pelleted antibody-antigen conjugates were treated with $50 \mu \mathrm{l}$ of Laemmli buffer and heated at $100{ }^{\circ} \mathrm{C}$ for $5 \mathrm{~min}$. The samples were run in electrophoresis, transferred to nitrocellulose membranes, and probed with HRP-labeled streptavidin. Bound HRP streptavidin was detected using a chemiluminescent detection system (ECL, Amersham).

\section{Sequence analysis of the $63 \mathrm{kDa}$ protein N-terminal}

The lysates of non-capacitated sperm cells were immunoprecipitated using an antibody against the ADAM15 carboxyl-domain. The immunoprecipitated material was solubilized with Laemmli buffer containing $10 \mathrm{mM}$ DTT, run in 10\% SDS-PAGE, and blotted onto a PVDF membrane. The $\mathrm{NH}_{2}$-terminal sequence of a $63 \mathrm{kDa}$ protein band was determined by automated Edman degradation on a gas-phase protein sequencer (LF 3000, Beckman Instruments, Santa Clara, CA, USA) equipped with an on-line Beckman System Gold high-performance liquid chromatography system. HLPC equipment included a model 126 pump and a 168 diode array detector, set at 268 y $293^{\mathrm{Q} 4} \mathrm{~nm}$ for signal and reference respectively. The HPLC column was a Beckman Spherogel Micro PTH $(2 \times 150 \mathrm{~mm})$. Standard Beckman sequencing reagents were used for the analysis.

\section{Superovulation and egg recovery}

The eggs were obtained from the oviducts of 6 to 8 -week-old female hamsters. Superovulation was induced by subcutaneous injection of $15 \mathrm{IU}$ of pregnant mare's serum gonadotropin (PMSG) followed by $15 \mathrm{IU}$ of human chorionic gonadotropin (hCG) $56 \mathrm{~h}$ later. The animals were killed 15-17 $\mathrm{h}$ post-hCG. The uterine ovary-salpinge-horn complexes were dissected, eggs removed from the ampulla of the oviduct, and collected in MCM-PL medium supplemented with $\mathrm{KCl}(2.7 \mathrm{mM})$ and $3 \%$ BSA (MCM-PLKA). The ampulla of each oviduct was punctured, the cumulus mass extruded and placed in $0.1 \%$ hyaluronidase in the MCM-PLKA medium for $7 \mathrm{~min}$ at $37^{\circ} \mathrm{C}$ in order to remove cumulus cells. The cumulus-free eggs were then washed four times for 3 min each using the MCM-PLKA medium. The ZP was removed by egg being incubated in the MCM-PLKA medium containing $0.025 \%$ trypsin for $5-7 \mathrm{~min}$ at $37^{\circ} \mathrm{C}$. Immediately, ZP-free eggs were placed in $0.15 \%$ trypsin inhibitor for $10 \mathrm{~min}$ and washed three times by transfer through drops of MCM-PLKA (Sanchez-Gutierrez et al. 2002).

\section{IVF and assessment of sperm binding and fusion}

Initially, the spermatozoa were capacitated in the presence of different dilution of the anti-acrogranin antibody (1:10 to $1: 50$ ) in the MCM-PLK medium, 30 min before co-incubation with 
ZP-free sperm eggs. The eggs and capacitated sperm (see above) were co-incubated in $200 \mu \mathrm{l}$ drops (20 eggs per fertilization drop added with $10 \mu$ of capacitated sperm) for $3 \mathrm{~h}$. After gametes co-incubation, eggs were washed three times in MCM-PLK medium containing 3\% BSA to remove any loosely attached sperm. The eggs were then fixed $(\mathrm{v} / \mathrm{v})$ with freshly prepared $3.0 \%$ formaldehyde in PBS for $1 \mathrm{~h}$. The eggs were washed twice with PBS and then stained with Hoechst $33342(20 \mu \mathrm{g} / \mathrm{ml}$ PBS$)$ for $30 \mathrm{~min}$ and finally washed three to four times with PBS for $15 \mathrm{~min}$ each. The stained eggs were mounted on a glass slide using Gelvatol as the mounting medium. The sperm-egg binding was documented using a phase-contrast images. Fluorescence images of decondensed nuclei of spermatozoa were taken in order to define whether the sperm had been incorporated into the egg's cytoplasm.

\section{Cell culture and lysis}

The human MCF7 and MDA-MB-231 breast cancer cells were cultured using DMEM supplemented with $3.7 \mathrm{~g} / \mathrm{l}$ sodium bicarbonate, $5 \%$ fetal bovine serum (FBS). They were kept at $37{ }^{\circ} \mathrm{C}$ under a humidified atmosphere containing $5 \% \mathrm{CO}_{2}$ and $95 \%$ air. When cells were confluent, the medium was eliminated by aspiration and cells were solubilized in RIPA buffer (50 mM HEPES, pH 7.4, $150 \mathrm{mM} \mathrm{NaF,} 10 \mathrm{mM}$ sodium pyrophosphate, $10 \%$ glycerol, $1 \%$ Triton $X-100,1 \%$ sodium deoxycholate, $1.5 \mathrm{mM} \mathrm{MgCl} 2,0.1 \% \mathrm{SDS}$, and protease inhibitors). The cell lysates were clarified by centrifugation at $12000 \mathrm{~g}$ for $10 \mathrm{~min}$ at $4{ }^{\circ} \mathrm{C}$. The supernatants were transferred to fresh tubes and protein levels determined by Bradford protein assay.

\section{Co-immunoprecipitation}

Co-immunoprecipitation experiments were carried out using the Pierce Crosslink Immunoprecipitation Kit (Pierce) following the manufacturer's instructions. Briefly, $10 \mu \mathrm{g}$ of anti-Adam15 or anti-Acrogranin antibodies were cross-linked with protein $\mathrm{A} / \mathrm{G}$ plus agarose and then combined with $500 \mu \mathrm{g}$ of precleared extracts from MCF7 and MDA-MB-231 breast cancer cells. The samples were then incubated under constant stirring for $12 \mathrm{~h}$ at $4{ }^{\circ} \mathrm{C}$. The proteins bound to the respective antibodies were eluted and recovered at low speed centrifugation (i.e. 1000-3000 g). Laemmli buffer (pH 10) was added to the eluted proteins and boiled for $5 \mathrm{~min}$. The proteins were separated by SDS-PAGE, transferred to nitrocellulose membranes, and immunoblotted.

\section{Results}

\section{Primary structure of guinea pig ADAM15 exhibits high homology with human ADAM15}

To determine whether guinea pig ADAM15 exhibits similar domains to ADAM15 of different species, we compared the primary structure of ADAM15 from human, mouse, and rat to the predicted sequence of guinea pig (Supplementary Figure 1, see section on supplementary data given at the end of this article).

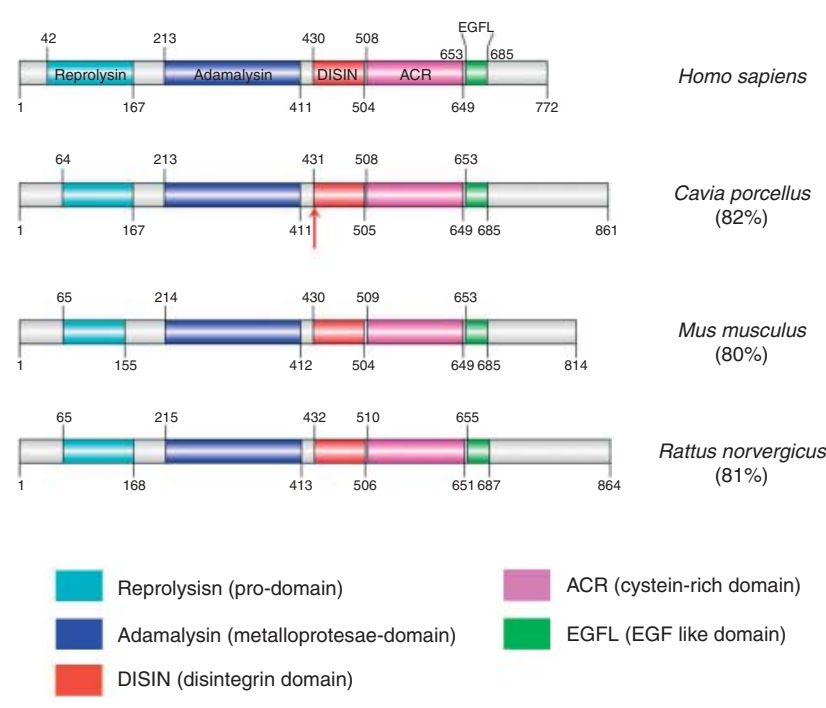

Figure 1 ADAM15 in mammals contains similar domains. Schematic representation of the structural domains of ADAM from human (Homo sapiens), guinea pig (Cavia porcellus), mouse (Mus musculus), and rat (Rattus norvegicus). Each sequence was aligned and compared with respect to human ADAM15 (see Supplementary Figure 1). The numbers correspond to the first amino acid that limits each domain, which were illustrated using the software DOG 2.0. It was found that the domains show a similar distribution in guinea pig, mouse, and rat compared with human ADAM15. In parenthesis is described the percentage of homology compared with human ADAM15. The black arrow indicates the site where starts the mature protein (aa 430-861).

We found a high homology between ADAM15 from guinea pig and human (82\%), a similar degree of homology was found when human ADAM15 was compared with mouse (80\%) and rat (81\%) (Fig. 1). Comparison of the predicted aminoacid sequence revealed that, as in human, ADAM15 from guinea pig as well as from rat and mouse is composed of four major domains: the pro-domain (Reprolysin domain), a metalloprotease domain (adamalysin), a disintegrin domain, and a cysteine-rich domain (Fig. 1). All of them has a high degree of homology (Supplementary Figure 1), though the cytoplasmic domain is larger in rat, and guinea pig (Fig. 1 and Supplementary Figure 1).

\section{ADAM15 is present in guinea pig spermatozoa and is processed during epididymal maturation}

It has been previously shown that ADAM1, ADAM2, ADAM3, ADAM15, and ADAM24 are first expressed in the sperm cell precursors as large precursors that are subsequently processed by proteolysis, either within the testis or during sperm epidiymal transit (Blobel et al. 1990, Phelps et al. 1990, Linder et al. 1995, Lum \& Blobel 1997, Zhu et al. 2001, Pasten-Hidalgo etal. 2008). In this study, in order to determine whether ADAM15 is present in guinea pig spermatozoa as well as to define whether it is processed during epididymal sperm maturation, protein extracts from testes and sperm cells at different maturational stages were 

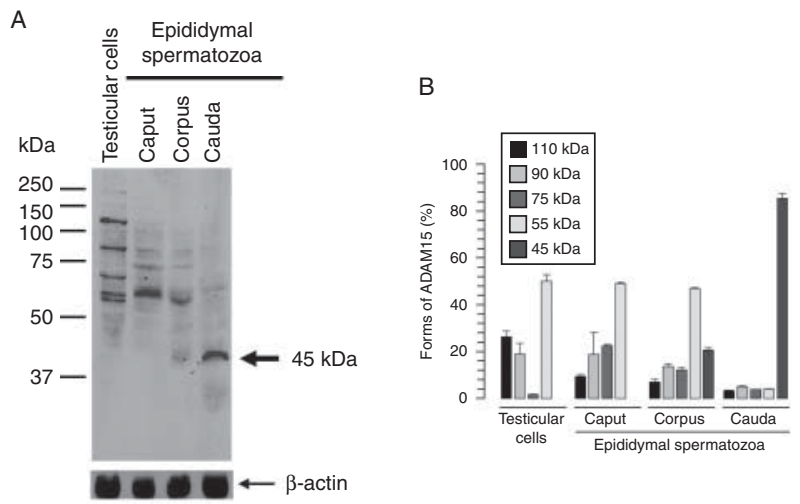

C
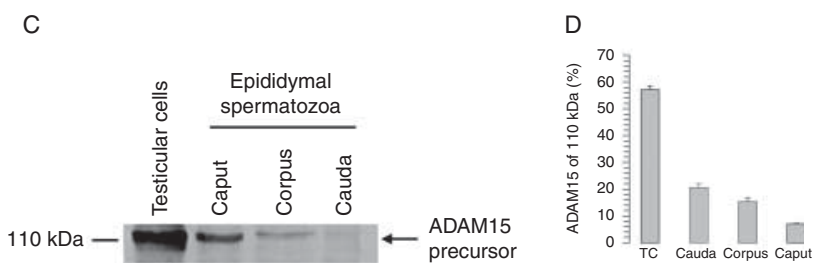

Figure 2 ADAM15 is processed during epididymal sperm maturation. The cells at different developmental stages were solubilized in lysis buffer. The solubilized proteins were boiled in Laemmeli buffer and subjected to SDS-PAGE, and blotted using antibodies against the carboxy $(A)$ or the amino $(C)$ domain of ADAM15. Images are representative of at least three independent experiments. The densitometric analysis of the different proteins detected is shown in (B) and (D) respectively. Error bars indicate mean \pm S.E.M.

immunoblotted against the carboxy domain of ADAM15 (ADAM15-CT). The three major bands of 110, 90, and $73 \mathrm{kDa}$ as well as a $56 \mathrm{kDa}$ doublet were detected in testicular cells extracts. However, in caput and corpus epididymal spermatozoa, the ADAM15 precursor (110 kDa) was detected as a residual band, whereas the other bands were well-defined. In contrast, the ADAM15CT antibody detected only a 45-kDa band in the extracts of epididymal cauda spermatozoa (Fig. 2A). A densitometric image analysis of the bands confirmed that the $45 \mathrm{kDa}$ is the main form of ADAM15 found in mature spermatozoa, while the others are just residual forms of ADAM15 (Fig. 2B). In order to determine whether these changes are related to the decrease in the $110 \mathrm{kDa}$ ADAM15 precursor, we used an antibody against its amino domain $\left(\right.$ ADAM15- $\left.\mathrm{NH}_{2}\right)$ to perform immunoblotting analysis. The densitometric analysis shows that the ADAM15 precursor decreased drastically from testicular cells to cauda epididymal spermatozoa, clearly indicating that ADAM15 is processed during epididymal spermatozoa maturation (Fig. 2C and D).

\section{ADAM15 localization in guinea pig spermatozoa}

The localization of ADAM15 in spermatozoa was assessed by immunofluorescence using antibodies against ADAM15-CT and ADAM15-NH $\mathrm{N}_{2}$. As can be seen in Fig. 3, using the ADAM15-CT antibody in epididimal caput spermatozoa, ADAM15 was mainly found on the acrosome region and along the flagellum with a rather low intensity. A similar distribution was observed for epididimal corpus and cauda spermatozoa, although ADAM15 was also found within the equatorial segment (Fig. 3). However, when the ADAM15- $\mathrm{NH}_{2}$ antibody was used, ADAM15 could be only detected on the acrosome region in epididimal caput spermatozoa, whereas both epididimal corpus and cauda spermatozoa did not show any fluorescence label (Fig. 3), thus corroborating the absence of the $110 \mathrm{kDa}$ form of ADAM15 in mature spermatozoa. We further characterized the localization of ADAM15 in non-capacitated, capacitated, and acrosome-reacted spermatozoa using the ADAM15-CT antibody. Immunofluorescence assays showed that ADAM15 is located in the acrosome region and equatorial segment as well as along the flagellum of non-capacitated and capacitated spermatozoa (Fig. 4A), whereas in acrosome-reacted spermatozoa, ADAM15 was lost together with the acrosome, but retained within the equatorial region and increased in the flagellar region (Fig. 4A). As the place of contact of the spermatozoa with the egg plasma membrane for sperm-egg fusion occurs at the level of equatorial segment (Flesch \& Gadella 2000), the localization of ADAM15 in the equatorial region might be of functional significance. Experiments for the antibody specificity were performed using pre-immune serum or only the secondary antibody. In both cases no fluorescence was detected (Fig. 4A).

Considering that we have previously reported that ADAM15 is processed during both capacitation and

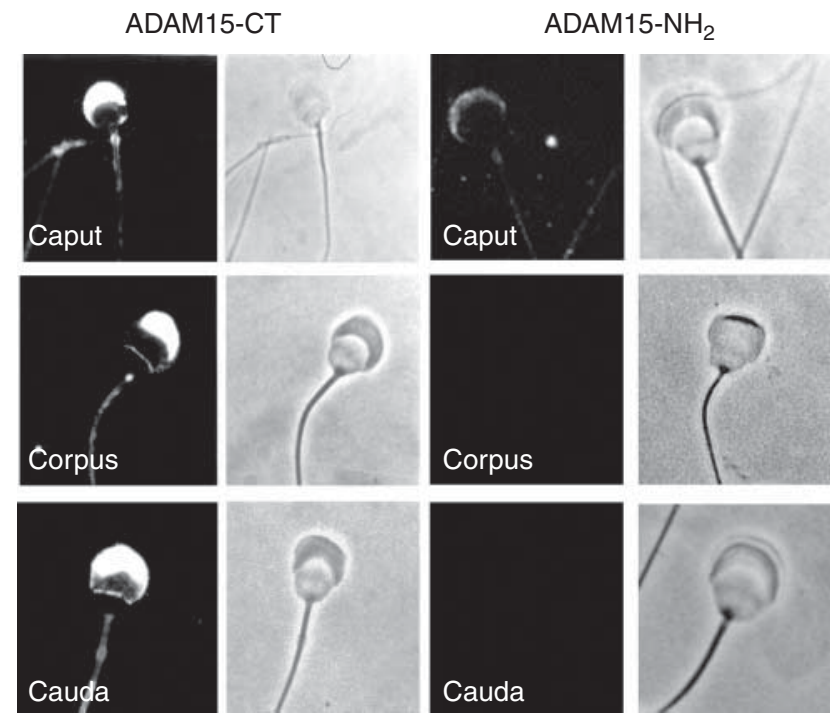

Figure 3 ADAM15 is located in epididymis of guinea pig spermatozoa. Spermatozoa isolated from different regions of epididymis (caput, corpus, and cauda) were fixed, permeabilized, and immunostained against the carboxy domain (ADAM15-TC) or amino domain (ADAM15- $\mathrm{NH}_{2}$ ) of ADAM15. The localization of ADAM15 was revealed using the adequated TRIC-labeled secondary antibody. Images are representative of at least three independent experiments. 
A

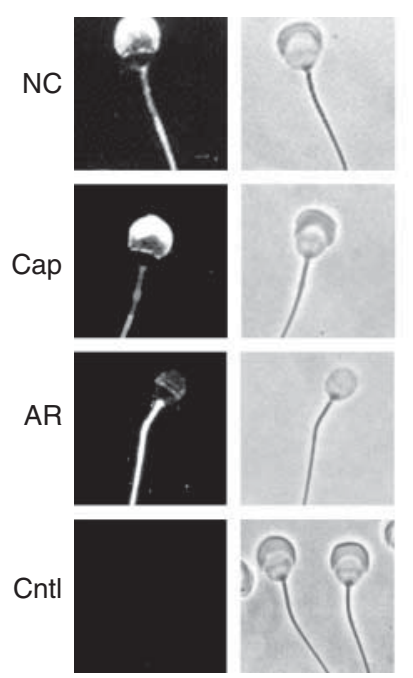

B

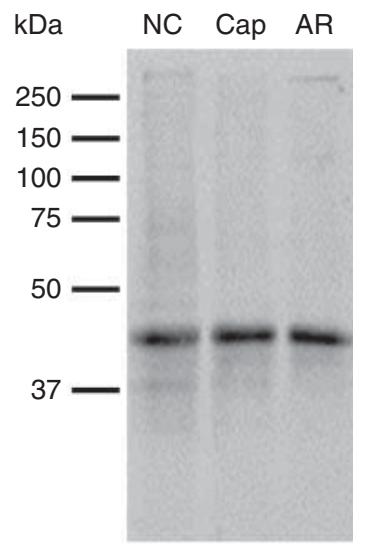

Figure 4 Localization of ADAM15 in guinea pig spermatozoa under different physiological states. (A) Non-capacitated (NC), capacitated (Cap), and acrosome-reacted (AR) spermatozoa were fixed, permeabilized, and immunostained against the carboxy-terminal domain of ADAM15 (ADAM15-TC). The localization of ADAM15 was revealed using the adequate TRIC-labeled secondary antibody. To control for the specificity, spermatozoa preparations were subjected to immunofluorescence without the addition of primary antibody (Cnt), as expected, no fluorescence was observed. (B) Non-capacitated (NC), capacitated (Cap), and acrosome-reacted (AR) spermatozoa were lysed.

The solubilized proteins were boiled in Laemmli buffer, subjected SDS-PAGE, and blotted using an antibody against the carboxy terminal domain of ADAM15. Images are representative of at least three independent experiments.

acrosome reaction in mouse spermatozoa (PastenHidalgo et al. 2008), we wanted to determine whether in guinea pig spermatozoa ADAM15 is similarly processed too. Immunoblotting analysis showed that in all samples assayed: non-capacitated, capacitated, and acrosome-reacted spermatozoa, a single band with a Mr of $45 \mathrm{kDa}$ was detected (Fig. 4B). Therefore, these results suggest that ADAM15 is not further processed during capacitation or acrosome reaction.

\section{ADAM15 forms a complex with acrogranin}

Previous studies have demonstrated that ADAMs have the ability to interact with other proteins to carry out their functions (White 2003). For instance, fertilin is a heterodimer composed by fertilins $\alpha$ (ADAM1) and $\beta$ (ADAM2). To investigate whether ADAM15 physically interacts with other proteins, ADAM15 was analyzed under non-reducing conditions. Immunoblots using the ADAM15-CT antibody and nonreduced protein extracts from non-capacitated, capacitated, and acrosomereacted sperm revealed only a band with a $\mathrm{Mr}$ of $154 \mathrm{kDa}$ (Fig. 5). As this band is not detected under disulfide reduction with $\beta$-mercaptoethanol (Fig. 4B),

this result indicates that ADAM15 is in the form of a high molecular weight complex via disulfide bonds.

It has been already shown that ADAM15 is part of a complex on the cell surface in MDA-MB-468 mammary epithelial carcinoma cells; however, its protein partner has not yet been identified (Krätzschmar et al. 1996). In this study, to determine the protein ADAM15 interaction with acrogranin, sperm surface proteins were biotinylated in vivo, solubilized, and then immunoprecipitated using the ADAM15-CT antibody. Three major bands of 45,57 , and $65 \mathrm{kDa}$ were detected in non-capacitated and acrosome-reacted spermatozoa when streptavidinHRP was used (Fig. 6A). The $45 \mathrm{kDa}$ band was identified as ADAM15 by immunoblotting using ADAM15-CT antibody (Fig. 6B), whereas the two others were subjected to Edman degradation for further identification. The $\mathrm{N}$-terminal sequence for the $65 \mathrm{kDa}$ protein was deduced as IRCPDDQVCPVACCP (Table 1). When compared with automate databases, it was identified as guinea pig acrogranin (Table 1). Then, in order to corroborate this, we performed western blotting assays against acrogranin, a single band of $65 \mathrm{kDa}$ could be detected in both non-capacitated and acrosome-reacted spermatozoa (Fig. 6C). Furthermore, western blotting analysis of immunoprecipitated proteins with the antiacrogranin antibody showed a single $45 \mathrm{kDa}$ band, which was revealed when the ADAM15-CT antibody was used (Fig. 6D). Conversely, western blotting analysis of immunoprecipitated proteins with the anti-ADAM15CT showed a protein band of $65 \mathrm{kDa}$ that was recognized by the anti-acrogranin antibody (Fig. 6E). Thus, ADAM15 and acrogranin are associated with non-capacitated and acrosome-reacted spermatozoa. Finally, to corroborate that ADAM15 and acrogranin form a complex, acrogranin was immunoprecipitated, and the proteins obtained were resolved by SDS-PAGE

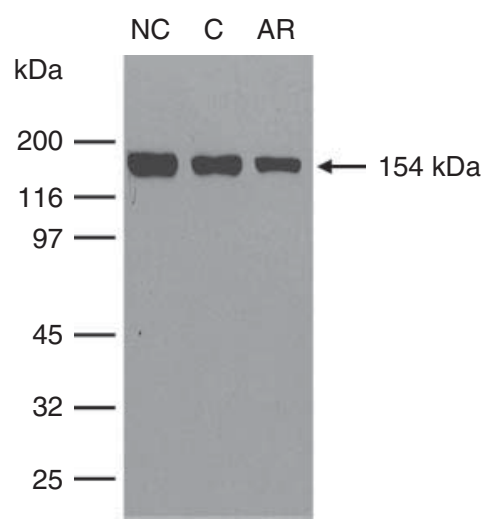

Figure 5 ADAM15 is associated with other protein. Non-capacitated (NC), capacitated (Cap) and acrosome-reacted (AR) spermatozoa were lysed. The solubilized proteins were subjected to western blotting against the carboxy terminal domain of ADAM15 under nonreductive conditions (without $\beta$-mercapatoethanol), and reduced SDS concentration $(0.5 \%)$. Image is representative of at least three independent experiments. 

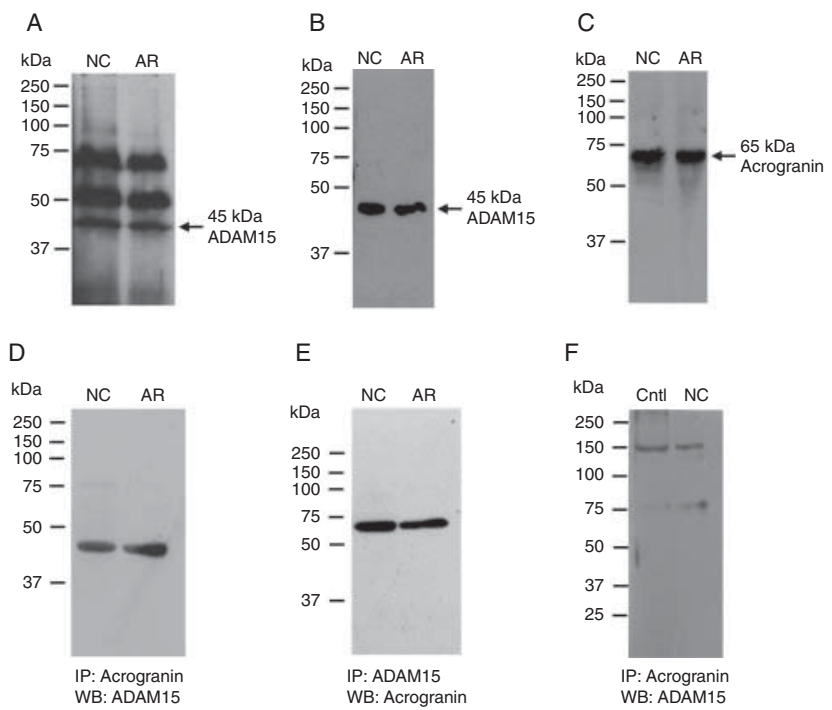

Figure 6 ADAM15 physically associates with acrogranin on the sperm cell surface. The surface of non-capacitated (NC) and acrosomereacted (AR) spermatozoa was biotinylated for $45 \mathrm{~min}$. The cells were then lysed and solubilized proteins immunoprecipitated using the ADAM15-CT antibody. Immunoprecipitates were blotted onto nitrocellulose membranes and revealed with (A) HRP-labeled streptavidin, (B) anti-ADAM15, or (C) anti- acrogranin. The physical interaction between ADAM15 and acrogranin was confirmed by co-immunoprecipitation. Solubilized proteins from non-capacitated and acrosome-reacted spermatozoa were immunoprecipitated with the acrogranin (D) or ADAM15-CT (E) antibody and then blotted onto nitrocellulose membranes. Immunoprecipitates were revealed using the ADAM15-CT (D) or the acrogranin (E) antibody. To determine whether form a complex of $154 \mathrm{kDa}$, solubilized proteins from noncapacitated (NC) spermatozoa were immunoprecipitated with the anti-acrogranin antibody, resolved under nonreductive condition, and reduced SDS concentration $(0.5 \%)$, blotted onto nitrocellulose membranes and revealed with anti-ADAM15-CT (F). Cntl, control of solubilized proteins resolved under nonreductive conditions, not immunoprecipitated. Images are representative of at least three independent experiments.

under no-reducing conditions. Western blotting analysis using the ADAM15-CT antibody shows a protein band with a Mr of $154 \mathrm{kDa}$ (Fig. 6F), identical to the protein band observed when ADAM15 was analyzed under no-reducing conditions (Figs 5 and $6 \mathrm{~F}$ ). To control for the specificity of the antibody used for immunoprecipitation, a nonrelated antibody (anti-tubulin) was used to immunoprecipitate biotinylated proteins instead of ADAM15-CT. As expected, no bands were detected by streptavidin-HRP or anti-acrogranin and anti-ADAM15 antibodies (data not shown).

\section{Acrogranin is present on the surface of spermatozoa and participates in fertilization}

It has been previously shown, by indirect immunofluorescence in permeabilized spermatozoa, that acrogranin is present in the acrosomal compartment of guinea pig spermatozoa (Anakwe \& Gerton 1990). In this study, we evaluated whether acrogranin is located on the surface of guinea pig spermatozoa. Living and swimming capacitated and acrosome-reacted spermatozoa were immunostained against acrogranin and analyzed by confocal microscopy. Optical sections at the mid-level of sperm cells showed fluorescence around the acrosome region, which corresponds to the cell plasma membrane (Fig. 7A). Nonetheless, when fixed and permeabilized spermatozoa were used, acrogranin was revealed inside the whole acrosome as previously reported (Anakwe \& Gerton 1990), as well as in whole flagellum (Fig. 7B). In living and swimming acrosomereacted spermatozoa, acrogranin was found mainly on the equatorial region and along the flagellum (Fig. 7C). These results indicate that acrogranin is present on the surface of acrosome and equatorial region of guinea pig spermatozoa, similar regions where ADAM15 was detected (Fig. 4).

The observation of acrogranin on the cell surface and its interaction with ADAM15 in acrosome-reacted sperm raise the possibility that acrogranin has a role during fertilization. To determine whether acrogranin is involved in sperm-egg binding, the antibody against acrogranin was used to compete for the interaction between capacitated sperm and zona pellucida-free eggs. As can be seen in Fig. 8, the acrogranin antibody decreased the sperm binding to zona pellucida-free eggs, in a dose-dependent manner. The sperm-egg interaction was decreased by $50 \%$ when a 1:10 antibody dilution was used. To control for the specificity of the antibody, the competitive binding assay was performed using an unrelated antibody. The results show a similar rate of fertilization between the control no treated with any antibody (Fig. 8, Cnt-1) and the treated

Table 1 Comparison of the $15 \mathrm{NH}_{2}$-terminal amino acid sequence of acrogranin from different mammalian species with the $\mathrm{NH}_{2}$-terminal amino acid of the guinea pig spermatozoa.

\begin{tabular}{lllll}
\hline Species & Sequences & Homology & & \\
Cavia porcellus & 1 IRCPDDQVCPVACCP 15 & & & gi[121616] \\
Cavia porcellus & 4 IRCPDDQVCPVACCP 18 & $100 \%$ & Acrogranin & gi [22252940] \\
Homo sapiens & 19 RCPDGQFCPVACC 31 & $84 \%$ & PC-cell-derived growth factor & gi[56109] \\
Rattus norvegicus & 20 CPDGQFCPVACC 31 & $83 \%$ & Epithelins 1 and 2 & gi[6680107] \\
Mus musculus & 20 CPDGQFCPVACC 31 & $83 \%$ & PC-cell-derived growth factor & . $31 \%$.
\end{tabular}

Alignment of the amino acid sequence of the $63 \mathrm{kDa}$ band. The first 15 amino acids were identified: IRCPDDQVCPVACCP. A search of this sequence on automated protein databases revealed a high degree of similarity (ranging between 83 and $100 \%$ identities) to the corresponding sequences of acrogranin from different species. 

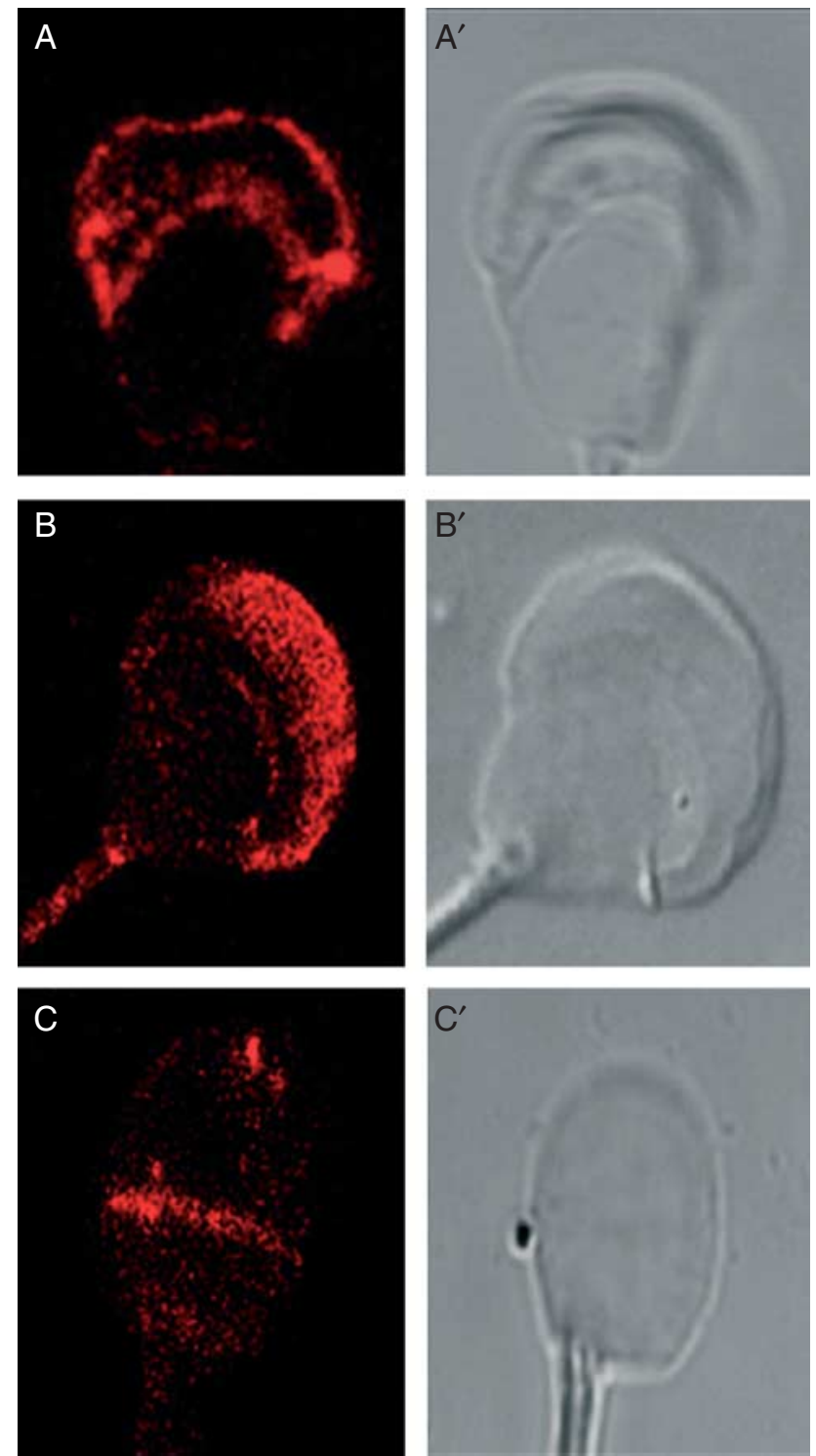

Figure 7 Acrogranin is located on the surface of living spermatozoa. Living and swimming spermatozoa were immunostained with acrogranin, fixed, mounted, and analyzed by confocal microscopy. (A) Anti-acrogranin staining of capacitated spermatozoa before fixation. (B) Capacitated spermatozoa stained after fixation.

(C) Acrosome-reacted spermatozoa stained before fixation. $A^{\prime}, B^{\prime}$, and $C^{\prime}$ are differential interface contrast images corresponding to $A, B$, and $C$ respectively. Images are representative of at least three independent experiments.

with an unrelated antibody (Fig. 8, Cnt-2). We thus conclude that the acrogranin associated with ADAM15, on the sperm plasma membrane, participates in the sperm-egg interaction.

\section{The ADAM15-acrogranin complex is also present in mammary epithelial carcinoma cells}

In light of our results as well as the previously reported participation of ADAM15 in fertilization
(Pasten-Hidalgo et al. 2008) and the involvement of both proteins in cell adhesion and migration in different cancer line cells (He \& Bateman 2003, He et al. 2003, Lendeckel et al. 2005, Kuefer et al. 2006), a possible role for the ADAM15-acrogranin complex in cell adhesion processes can be inferred. To test the possibility that ADAM 15 and acrogranin interacts with each other in cancer cell lines, the expression of both ADAM15 and acrogranin was first evaluated by western blotting in two different breast cancer cell lines, MDAMB-231 and MCF7. The antibody against ADAM15 detected a single protein band of $110 \mathrm{kDa}$ in both cancer cell lines (Fig. 9A), which corresponds to the molecular weight reported for the unprocessed ADAM15 (Krätzschmar et al. 1996). On the other hand, acrogranin was detected in both cell lines as a band of $\sim 90 \mathrm{kDa}$ (Fig. 9A), this molecular weight corresponds to the highly glycosylated form of acrogranin, which is found in different cancer cell lines (Zhou et al. 1993, He \& Bateman 2003). We next evaluated whether ADAM15 and acrogranin are associated in a complex in these two cancer cell lines. Using co-immunoprecipitation assays, we found that acrogranin indeed physically interacts with ADAM15. When acrogranin was immunoprecipitated, ADAM15 could be detected by western blotting, and vice versa (Fig. 9B).

\section{Discussion}

In mouse spermatozoa, ADAM15 is processed through the course of epididymal maturation and during

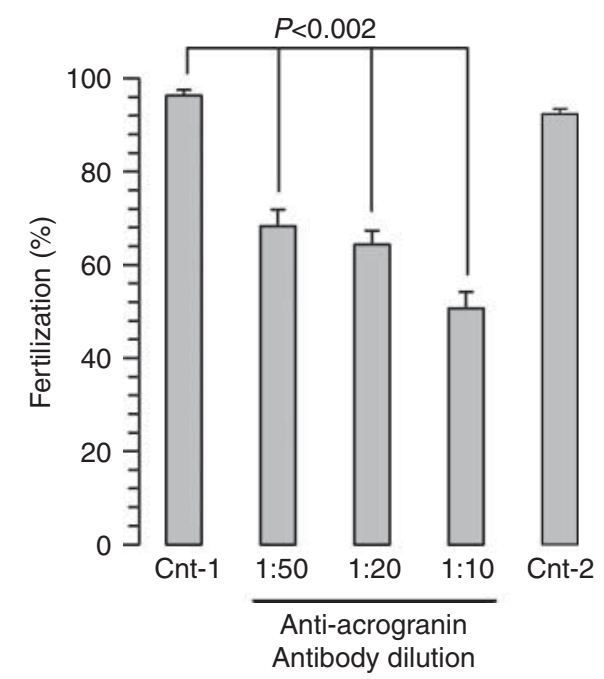

Figure 8 Fertilization is interfered using an anti-acrogranin antibody. Capacitated spermatozoa previously treated with anti-acrogranin antibody for $30 \mathrm{~min}$ at different dilutions were incubated for $3 \mathrm{~h}$ with ZP-free hamster eggs and the incorporation of spermatozoa into egg's cytoplasm evaluated. Cnt1, control with any antibody added. Cnt2, control where spermatozoa were incubated with a nonrelated antibody (1:10). Graph represents the average of four experiments per sample \pm s.E.M., a total of 80 eggs were fertilized per sample. 
A
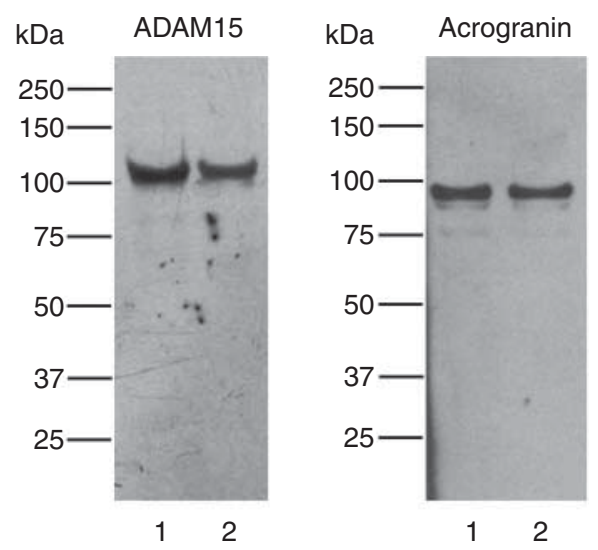

B

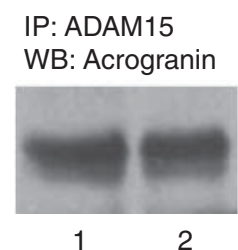

IP: Acrogranin WB: ADAM15

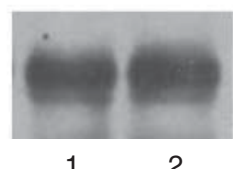

1

Figure 9 ADAM15 and acrogranin physically interact in a complex in two different human breast cancer cells lines. (A) Protein extracts of two breast cancer cell lines, MDA-MB-231 (1) and MCF7 (2), were immunoblotted against ADAM15-CT or acrogranin. (B) Protein extracts of MDA-MB-231 and MCF7 cells were immunoprecipitated with anti-acrogranin antibody and revealed with anti-ADAM15-CT domain antibody or immunoprecipitated with anti-ADAM15-CT antibody and revealed with anti-acrogranin antibody. Images are representative of at least three independent experiments.

acrosome reaction. The $\mathrm{N}$-terminal domain of ADAM15 is removed stepwise in a process starting while still in the testis, continues during epididymal transit, and finishes during acrosomal reaction in the female reproductive tract (Pasten-Hidalgo et al. 2008). However, although a similar stepwise removal of the $\mathrm{N}$-terminal domain takes place in guinea pig spermatozoa, herein we show that by the time spermatozoa go through cauda epididymis, the processing of ADAM15 has already been completed; therefore the ADAM15 carried by the spermatozoa reaching the female reproductive tract is the $45 \mathrm{kDa}$ mature form. A similar maturation process in spermatozoa before reaching female reproductive tract has already been reported for fertilin- $\alpha$ (ADAM1) (Lum \& Blobel 1997). The biological significance of the differences in the processing of ADAM15 among species is currently unknown. However, because only traces of the others forms of ADAM15 were detected once the $45 \mathrm{kDa}$ form appears, a plausible explanation is that in guinea pig the protease responsible for the processing is already present in testicular cells and secreted by epididydimal cells, whereas in mouse it is absent. Therefore, ADAM15 is kept as a $75 \mathrm{kDa}$ form in mouse

spermatozoa until capacitation and processed during acrosome reaction (Pasten-Hidalgo et al. 2008). Because partial proteolytic digestion performed with trypsin on testicular spermatozoa converts ADAM2 precursor into a form that resembles mature ADAM2, and because during acrosome reaction, serin endoproteases with trypsin-like activity are secreted (Mao \& Yang 2013), it is possible that a trypsin-like protease is involved in the processing of ADAM15 (Blobel et al. 1990, Lum \& Blobel 1997).

The comparison of the predicted sequence of guinea pig ADAM15 with that of human, mouse, and rat clearly shows that the full (unprocessed) form of ADAM15 from guinea pig has the same multifunctional domains similar to that in human, mouse, and rat (Supplementary Figure 1). However, after the last auto proteolytic step, the mature form of ADAM15 (45 kDa) is composed of the disintegrin, the cysteine-rich, the EGF-like, and the cytoplasmic domains (Fig. 1). The presence of the cysteine-rich region is relevant for the interaction of ADAM15 with acrogranin, because the later is composed of 7.5 tandem repeats of 12 cysteinyl motif (De Muynck \& Van Damme 2011), allowing both proteins to interact with each other through disulfide bonds. More studies are required to know the specific sites of interaction.

Acrogranin was originally identified as a secreted protein of $68 \mathrm{kDa}$ that because its high level of glycosylation behaved as a $90 \mathrm{kDa}$ protein (He et al. 2003). Interestingly, acrogranin has already been reported as a protein of $68 \mathrm{kDa}$ in guinea pig spermatozoa (Anakwe \& Gerton 1990). In this study, acrogranin was detected using a similar Mr of $65 \mathrm{kDa}$. Considering that glycosilation increases the molecular weight of acrogranin, it is very likely that the principal form of acrogranin in guinea pig spermatozoa is the nonglycosylated form.

Once spermatozoa leave the testis and enter the epididymis, they begin the maturation process. It continues along the epididymis and finishes within the female reproductive tract, where they undergo capacitation and acrosomal reaction. Remarkably, despite all the remodeling of the plasma membrane occurring through this maturation process (Tulsiani \& Abou-Haila 2011), in this study we show that after the acrosome reaction took place, both ADAM15 and acrogranin remain localized on the equatorial segment. Given the sperm-egg interaction takes place at the level of the equatorial segment of spermatozoa (Flesch \& Gadella 2000), our findings that ADAM15 and acrogranin physically interact in a protein complex in guinea pig spermatozoa (Fig. 5) and that the sperm-egg interaction is interfered with an antibody against acrogranin (Fig. 7), or with a peptide against the small putative regions of desintegrin domain of ADAM15 (Pasten-Hidalgo et al. 2008), support the idea that the ADAM15/acrogranin complex might be important as a mediator of gamete interaction during fertilization. Moreover, our results suggest that 
acrogranin might be an accessory protein of ADAM15 that participates in cell adhesion, this is supported by the fact that, besides spermatozoa, the ADAM15/Acrogranin complex is also present in two breast cancer cell lines (Fig. 9), and by the fact that blastocyst adhesion is blocked by antibodies against acrogranin whereas addition of purified acrogranin increases their adhesion (Qin et al. 2005). Considering that acrogranin lacks a transmembrane region, we suggest that one of the functions of ADAM15 in the complex is to serve as an anchor for acrogranin on the sperm surface. Such interaction may occur through a disulfide bond between the sulfhydryl-rich domain of ADAM15 and the cysteinerich motif of acrogranin, in a similar way than reported for molecules involved in viral fusion proteins (White 1992, White et al. 2008). Overall, our results favor the idea that ADAM15 and acrogranin play a pivotal role in fertilization. In view of the similitude of ADAM15 between guinea pig and mouse, we suggest that in guinea pig ADAM15 might be also involved in spermegg binding as in mice. We are presently carrying out homolog fertilization experiments to demonstrate that ADAM15 together with acrogranin participate in the sperm-egg binding process. However, those results will be presented in another report.

The distribution of sperm surface antigens during capacitation and acrosome reaction has been well documented for proteins such as IZUMO1 (Sosnik et al. 2009), CRISP1 (Da Ros et al. 2004), and PH20 (Myles \& Primakoff 1984), these proteins migrate after capacitation changing their localization. In a previous work, we have also shown that ADAM15 migrate from acrosome to the post-acrosomal region of mouse sperm before acrosome reaction (Pasten-Hidalgo et al. 2008). Despite the importance of these proteins in sperm-egg interaction, little is known about the significance and the molecular regulation of this migration event. One explanation comes from the relocation of IZUMO1; its migration is dependent on the actin cytoskeleton and testis-specific serine kinase (Tssk) (Sosnik et al. 2009). However, actin binding domains or actin-adaptor proteins that link IZUMO1 or ADAM15, CRISP1, and $\mathrm{PH} 20$ with the actin cytoskeleton have not been reported for these proteins. Therefore, we hypothesized that the cytoskeleton acts as a barrier that prevent proteins migration before capacitation or acrosome reaction, and that the intricate actin depolymerization and polymerization movements described in the sperm head during capacitation (Brener et al. 2003, Dvorakova et al. 2005) release the proteins allowing their migration. It is important to note that ADAM15, IZUMO1, PH20, and CRISP1 are located in a sperm plasma membrane domain different to the domains where they act during fertilization (Myles \& Primakoff 1984, Da Ros et al. 2004, Pasten-Hidalgo et al. 2008, Sosnik et al. 2009). The migration of these proteins matches both the change in the functional state of the sperm and the changes in these membrane domains. For example, one hallmark of capacitation is the reorientation of lipid rafts toward the apical acrosome region, this change is relevant for ZP-binding and ZP-induced acrosome reaction (van Gestel et al. 2005, Boerke et al. 2008, 2014) and that may facilitate protein migration and the activation of ADAM15, IZUMO1, CRISP1, and PH20. It is very likely that changes in both actin cytoskeleton and lipid rafts domains regulate the protein migration in sperm.

It is important to note that acrogranin is a secreted autocrine growth factor. It has been found to interact on the outer surface of plasma membrane of 3T3 fibroblast and epithelial PC cells as a ligand for an unknown $120 \mathrm{kDa}$ protein receptor (Xia \& Serrero 1998). In our co-immunoprecipitation assays, using the breast cancer cell lines MCF7 and MDA-MB-231, was found that ADAM15 (110 kDa) physically interacts with acrogranin, therefore we suggest that ADAM15 could be the $120 \mathrm{kDa}$ protein associated with acrogranin in epithelial cell and fibroblast (Xia \& Serrero 1998). Also, we suggest that acrogranin could be the protein associated with ADAM 15 on the surface of the breast cancer cell line MDA-MB-468 (Krätzschmar et al. 1996). The wide expression of ADAM15 and acrogranin in tissues and cells (Edwards et al. 2008, De Muynck \& Van Damme 2011) suggests that the ADAM15-acrogranin complex may be of broad significance in many biological processes besides fertilization, like for instance, development and cancer. ADAM15 and acrogranin have been related to cell adhesion exerting apoptosis resistance and survival effects on different cell lines $(\mathrm{He}$ et al. 2002, Guerra et al. 2007, Ryan et al. 2009, Böhm et al. 2010, Cuevas-Antonio et al. 2010, Rosen et al. 2011, Hou et al. 2013). These effects could be related to the modulation of focal adhesion kinase signaling through activation of Src (Fried et al. 2012, Böhm et al. 2013) as well as the formation of a complex involving paxillin, FAK, and ERK (He et al. 2002, Monami et al. 2006, Ryan et al. 2009). Remarkably, a recent report has suggested the presence of phosphorylated FAK in horse spermatozoa (Gonzalez-Fernandez et al. 2013) and findings in our laboratory has indicated an increase in the phosphorylation of FAK and paxillin during sperm capacitation (data not shown).

In conclusion, our work shows that ADAM15 physically interacts with acrogranin and that this interaction has a biological meaning in fertilization. Acrogranin is a multifunctional protein, which has been found to be involved in cell growth, wound repair, tumorigenesis, inflammation, neurodevelopment, and neurodegeneration, and since ADAM15 is also involved in several of these biological processes, raising an interesting interrogation about what is the biological importance of the complex form by ADAM15/acrogranin. The mechanism of action of acrogranin is still largely unknown, especially in mammalian spermatozoa; 
however, its interaction with ADAM15 could give new understanding of the biology of this protein and impact several areas of research, such as capacitation, fertilization, or cell migration.

\section{Supplementary data}

This is linked to the online version of the paper at http://dx.doi. org/10.1530/REP-14-0179.

\section{Declaration of interest}

The authors declare that there is no conflict of interest that could be perceived as prejudicing the impartiality of the research reported.

\section{Funding}

This work was supported by a CONACYT grant 237298 to EOHG.

\section{Acknowledgements}

The authors thank $M$ en $C$ Jaime Escobar and Unidad de Microscopia Confocal (Dpto. Biología Celular, CINVESTAVIPN) for providing the confocal facilities. They also thank Dr J Alfredo Mendez for critical review of this manuscript.

\section{References}

Anakwe OO \& Gerton GL 1990 Acrosome biogenesis begins during meiosis: evidence from the synthesis and distribution of an acrosomal glycoprotein, acrogranin, during guinea pig spermatogenesis. Biology of Reproduction 42 317-328. (doi:10.1095/biolreprod42.2.317)

Blobel CP, Myles DG, Primakoff P \& White JM 1990 Proteolytic processing of a protein involved in sperm-egg fusion correlates with acquisition of fertilization competence. Journal of Cell Biology 111 69-78. (doi:10.1083/jcb.111.1.69)

Boerke A, Tsai PS, Garcia-Gil N, Brewis IA \& Gadella BM 2008 Capacitation-dependent reorganization of microdomains in the apical sperm head plasma membrane: functional relationship with zona binding and the zona-induced acrosome reaction. Theriogenology $\mathbf{7 0}$ 1188-1196. (doi:10.1016/j.theriogenology.2008.06.021)

Boerke A, van der Lit J, Lolicato F, Stout TA, Helms JB \& Gadella BM 2014 Removal of GPI-anchored membrane proteins causes clustering of lipid microdomains in the apical head area of porcine sperm. Theriogenology 81 613-624. (doi:10.1016/j.theriogenology.2013.11.014)

Böhm B, Hess S, Krause K, Schirner A, Ewald W, Aigner T \& Burkhardt H 2010 ADAM15 exerts an antiapoptotic effect on osteoarthritic chondrocytes via up-regulation of the X-linked inhibitor of apoptosis. Arthritis and Rheumatism 62 1372-1382.

Böhm BB, Freund I, Krause K, Kinne RW \& Burkhardt H 2013 ADAM15 adds to apoptosis resistance of synovial fibroblasts by modulating focal adhesion kinase signaling. Arthritis and Rheumatism 65 2826-2834.

Bradford MM 1976 A rapid and sensitive method for the quantitation of microgram quantities of protein utilizing the principle of protein-dye binding. Analytical Biochemistry 72 248-254. (doi:10.1016/00032697(76)90527-3)

Brener E, Rubinstein S, Cohen G, Shternall K, Rivlin J \& Breitbart H 2003 Remodeling of the actin cytoskeleton during mammalian sperm capacitation and acrosome reaction. Biology of Reproduction 68 837-845. (doi:10.1095/biolreprod.102.009233)
Chen MS, Tung KS, Coonrod SA, Takahashi Y, Bigler D, Chang A, Yamashita Y, Kincade PW, Herr JC \& White JM 1999 Role of the integrinassociated protein CD9 in binding between sperm ADAM 2 and the egg integrin alpha6beta1: implications for murine fertilization. PNAS $\mathbf{9 6}$ 11830-11835. (doi:10.1073/pnas.96.21.11830)

Cho C, Bunch DO, Faure JE, Goulding EH, Eddy EM, Primakoff P \& Myles DG 1998 Fertilization defects in sperm from mice lacking fertilin ß. Science 281 1857-1859. (doi:10.1126/science.281.5384.1857)

Cuevas-Antonio R, Cancino C, Arechavaleta-Velasco F, Andrade A, Barron L, Estrada I, Fernandez RL, Olguin V, Ruiz S, Imani $F$ et al. 2010 Expression of progranulin (Acrogranin/PCDGF/Granulin-Epithelin Precursor) in benign and malignant ovarian tumors and activation of MAPK signaling in ovarian cancer cell line. Cancer Investigation $\mathbf{2 8}$ 452-458. (doi:10.3109/07357900903346455)

Da Ros VG, Munuce MJ, Cohen DJ, Marin-Briggiler Cl, Busso D, Visconti PE \& Cuasnicu PS 2004 Bicarbonate is required for migration of sperm epididymal protein DE (CRISP-1) to the equatorial segment and expression of rat sperm fusion ability. Biology of Reproduction $\mathbf{7 0}$ 1325-1332. (doi:10.1095/biolreprod.103.022822)

De Muynck L \& Van Damme P 2011 Cellular effects of progranulin in health and disease. Journal of Molecular Neuroscience 45 549-560. (doi:10.1007/s12031-011-9553-z)

Dvorakova K, Moore HD, Sebkova N \& Palecek J 2005 Cytoskeleton localization in the sperm head prior to fertilization. Reproduction $\mathbf{1 3 0}$ 61-69. (doi:10.1530/rep.1.00549)

Edwards DR, Handsley MM \& Pennington CJ 2008 The ADAM metalloproteinases. Molecular Aspects of Medicine 29 258-289. (doi:10.1016/j.mam.2008.08.001)

Evans JP 2012 Sperm-egg interaction. Annual Review of Physiology 74 477-502. (doi:10.1146/annurev-physiol-020911-153339)

Evans JP, Schultz RM \& Kopf GS 1995 Mouse sperm-egg plasma membrane interactions: analysis of roles of egg integrins and the mouse sperm homologue of PH-30 (fertilin) $\beta$. Journal of Cell Science 108 3267-3278.

Flesch FM \& Gadella BM 2000 Dynamics of the mammalian sperm plasma membrane in the process of fertilization. Biochimica et Biophysica Acta 1469 197-235. (doi:10.1016/S0304-4157(00)00018-6)

Fried D, Bohm BB, Krause K \& Burkhardt H 2012 ADAM15 protein amplifies focal adhesion kinase phosphorylation under genotoxic stress conditions. Journal of Biological Chemistry 287 21214-21223. (doi:10.1074/jbc.M112.347120)

van Gestel RA, Brewis IA, Ashton PR, Helms JB, Brouwers JF \& Gadella BM 2005 Capacitation-dependent concentration of lipid rafts in the apical ridge head area of porcine sperm cells. Molecular Human Reproduction 11 583-590. (doi:10.1093/molehr/gah200)

Gonzalez-Fernandez L, Macias-Garcia B, Loux SC, Varner DD \& Hinrichs K 2013 Focal adhesion kinases and calcium/calmodulindependent protein kinases regulate protein tyrosine phosphorylation in stallion sperm. Biology of Reproduction 88 138. (doi:10.1095/biolreprod.112.107078)

Guerra RR, Kriazhev L, Hernandez-Blazquez FJ \& Bateman A 2007 Progranulin is a stress-response factor in fibroblasts subjected to hypoxia and acidosis. Growth Factors 25 280-285. (doi:10.1080/ 08977190701781222)

He Z \& Bateman A 2003 Progranulin (granulin-epithelin precursor, PC-cell-derived growth factor, acrogranin) mediates tissue repair and tumorigenesis. Journal of Molecular Medicine 81 600-612. (doi:10. 1007/s00109-003-0474-3)

He Z, Ismail A, Kriazhev L, Sadvakassova G \& Bateman A 2002 Progranulin (PC-cell-derived growth factor/acrogranin) regulates invasion and cell survival. Cancer Research 62 5590-5596.

He Z, Ong CH, Halper J \& Bateman A 2003 Progranulin is a mediator of the wound response. Nature Medicine 9 225-229. (doi:10.1038/nm816)

Herren B, Raines EW \& Ross R 1997 Expression of a disintegrin-like protein in cultured human vascular cells and in vivo. FASEB Journal 11 173-180.

Herren B, Garton KJ, Coats S, Bowen-Pope DF, Ross R \& Raines EW 2001 ADAM15 overexpression in NIH3T3 cells enhances cell-cell interactions. Experimental Cell Research 271 152-160. (doi:10.1006/ excr.2001.5353)

Hoffer AP \& Greenberg J 1978 The structure of the epididymis, efferent ductules and ductus deferens of the guinea pig: a light microscope study. Anatomical Record 190 659-677. (doi:10.1002/ar.1091900304) 
Hou Y, Chu M, Du FF, Lei JY, Chen Y, Zhu RY, Gong XH, Ma X \& Jin J 2013 Recombinant disintegrin domain of ADAM15 inhibits the proliferation and migration of Bel-7402 cells. Biochemical and Biophysical Research Communications 435 640-645. (doi:10.1016/j.bbrc.2013.05.037)

Krätzschmar J, Lum L \& Blobel CP 1996 Metargidin, a membrane-anchored metalloprotease-disintegrin protein with an RGD integrin binding sequence. Journal of Biological Chemistry 271 4593-4596.

Kuefer R, Day KC, Kleer CG, Sabel MS, Hofer MD, Varambally S, Zorn CS, Chinnaiyan AM, Rubin MA \& Day ML 2006 ADAM15 disintegrin is associated with aggressive prostate and breast cancer disease. Neoplasia 8 319-329. (doi:10.1593/neo.05682)

Laemmli UK 1970 Cleavage of structural proteins during the assembly of the head of bacteriophage T4. Nature 227 680-685. (doi:10.1038/ 227680a0)

Lendeckel U, Kohl J, Arndt M, Carl-McGrath S, Donat H \& Rocken C 2005 Increased expression of ADAM family members in human breast cancer and breast cancer cell lines. Journal of Cancer Research and Clinical Oncology 131 41-48. (doi:10.1007/s00432-004-0619-y)

Linder B, Bammer S \& Heinlein UA 1995 Delayed translation and posttranslational processing of cyritestin, an integral transmembrane protein of the mouse acrosome. Experimental Cell Research 221 66-72. (doi:10.1006/excr.1995.1353)

Lum L \& Blobel CP 1997 Evidence for distinct serine protease activities with a potential role in processing the sperm protein fertilin. Developmental Biology 191 131-145. (doi:10.1006/dbio.1997.8609)

Mao HT \& Yang WX 2013 Modes of acrosin functioning during fertilization. Gene 526 75-79. (doi:10.1016/j.gene.2013.05.058)

Monami G, Gonzalez EM, Hellman M, Gomella LG, Baffa R, lozzo RV \& Morrione A 2006 Proepithelin promotes migration and invasion of 5637 bladder cancer cells through the activation of ERK $1 / 2$ and the formation of a paxillin/FAK/ERK complex. Cancer Research 66 7103-7110. (doi:10. 1158/0008-5472.CAN-06-0633)

Myles DG \& Primakoff P 1984 Localized surface antigens of guinea pig sperm migrate to new regions prior to fertilization. Journal of Cell Biology 99 1634-1641. (doi:10.1083/jcb.99.5.1634)

Myles DG, Kimmel LH, Blobel CP, White JM \& Primakoff P 1994 Identification of a binding site in the disintegrin domain of fertilin required for sperm-egg fusion. PNAS 91 4195-4198. (doi:10.1073/pnas.91.10.4195)

Nishimura H, Cho C, Branciforte DR, Myles DG \& Primakoff P 2001 Analysis of loss of adhesive function in sperm lacking cyritestin or fertilin ß. Developmental Biology 233 204-213. (doi:10.1006/dbio.2001.0166)

Pasten-Hidalgo K, Hernandez-Rivas R, Roa-Espitia AL, Sanchez-Gutierrez M, Martinez-Perez F, Monrroy AO, Hernandez-Gonzalez EO \& Mujica A 2008 Presence, processing, and localization of mouse ADAM15 during sperm maturation and the role of its disintegrin domain during sperm-egg binding. Reproduction 136 41-51. (doi:10.1530/REP-07-0300)

Phelps BM \& Myles DG 1987 The guinea pig sperm plasma membrane protein, $\mathrm{PH}-20$, reaches the surface via two transport pathways and becomes localized to a domain after an initial uniform distribution. Developmental Biology 123 63-72. (doi:10.1016/0012-1606(87)90428-3)

Phelps BM, Koppel DE, Primakoff P \& Myles DG 1990 Evidence that proteolysis of the surface is an initial step in the mechanism of formation of sperm cell surface domains. Journal of Cell Biology 111 1839-1847. (doi:10.1083/jcb.111.5.1839)

Poghosyan Z, Robbins SM, Houslay MD, Webster A, Murphy G \& Edwards DR 2002 Phosphorylation-dependent interactions between ADAM15 cytoplasmic domain and Src family protein-tyrosine kinases. Journal of Biological Chemistry 277 4999-5007. (doi:10.1074/ jbc.M107430200)

Qin J, Diaz-Cueto L, Schwarze JE, Takahashi Y, Imai M, Isuzugawa K, Yamamoto S, Chang KT, Gerton GL \& Imakawa K 2005 Effects of progranulin on blastocyst hatching and subsequent adhesion and outgrowth in the mouse. Biology of Reproduction 73 434-442. (doi:10.1095/biolreprod.105.040030)
Rogers BJ \& Yanagimachi R 1975 Retardation of guinea pig sperm acrosome reaction by glucose: the possible importance of pyruvate and lactate metabolism in capacitation and the acrosome reaction. Biology of Reproduction 13 568-575. (doi:10.1095/biolreprod13.5.568)

Rosen EY, Wexler EM, Versano R, Coppola G, Gao F, Winden KD, Oldham MC, Martens LH, Zhou P, Farese RV Jr et al. 2011 Functional genomic analyses identify pathways dysregulated by progranulin deficiency, implicating Wnt signaling. Neuron 71 1030-1042. (doi:10.1016/ j.neuron.2011.07.021)

Rubinstein E, Ziyyat A, Wolf JP, Le Naour F \& Boucheix C 2006 The molecular players of sperm-egg fusion in mammals. Seminars in Cell \& Developmental Biology 17 254-263. (doi:10.1016/j.semcdb. 2006.02.012)

Ryan CL, Baranowski DC, Chitramuthu BP, Malik S, Li Z, Cao M, Minotti S, Durham HD, Kay DG, Shaw CA et al. 2009 Progranulin is expressed within motor neurons and promotes neuronal cell survival. BMC Neuroscience 10 130. (doi:10.1186/1471-2202-10-130)

Sanchez-Gutierrez M, Contreras RG \& Mujica A 2002 Cytochalasin-D retards sperm incorporation deep into the egg cytoplasm but not membrane fusion with the egg plasma membrane. Molecular Reproduction and Development 63 518-528. (doi:10.1002/mrd.10203)

Shamsadin R, Adham IM, Nayernia K, Heinlein UA, Oberwinkler H \& Engel W 1999 Male mice deficient for germ-cell cyritestin are infertile. Biology of Reproduction 61 1445-1451. (doi:10.1095/biolreprod61.6.1445)

Sosnik J, Miranda PV, Spiridonov NA, Yoon SY, Fissore RA, Johnson GR \& Visconti PE 2009 Tssk6 is required for Izumo relocalization and gamete fusion in the mouse. Journal of Cell Science 122 2741-2749. (doi:10.1242/jcs.047225)

Trejo R \& Mujica A 1990 Changes in calmodulin compartmentalization throughout capacitation and acrosome reaction in guinea pig spermatozoa. Molecular Reproduction and Development 26 366-376. (doi:10.1002/mrd.1080260412)

Tulsiani DR \& Abou-Haila A 2011 Molecular events that regulate mammalian fertilization. Minerva Ginecologica 63 103-118.

White JM 1992 Membrane fusion. Science 258 917-924. (doi:10.1126/ science.1439803)

White JM 2003 ADAMs: modulators of cell-cell and cell-matrix interactions. Current Opinion in Cell Biology 15 598-606. (doi:10.1016/ j.ceb.2003.08.001)

White JM, Delos SE, Brecher M \& Schornberg K 2008 Structures and mechanisms of viral membrane fusion proteins: multiple variations on a common theme. Critical Reviews in Biochemistry and Molecular Biology 43 189-219. (doi:10.1080/10409230802058320)

Xia X \& Serrero G 1998 Identification of cell surface binding sites for PC-cell-derived growth factor, PCDGF, (epithelin/granulin precursor) on epithelial cells and fibroblasts. Biochemical and Biophysical Research Communications 245 539-543. (doi:10.1006/bbrc.1998.8498)

Zhou J, Gao G, Crabb JW \& Serrero G 1993 Purification of an autocrine growth factor homologous with mouse epithelin precursor from a highly tumorigenic cell line. Journal of Biological Chemistry 268 10863-10869.

Zhu GZ, Myles DG \& Primakoff P 2001 Testase 1 (ADAM 24) a plasma membrane-anchored sperm protease implicated in sperm function during epididymal maturation or fertilization. Journal of Cell Science 114 1787-1794.

Received 2 April 2014

First decision 28 April 2014

Revised manuscript received 22 August 2014

Accepted 23 September 2014 